\title{
A Homeobox Gene Is Essential for Conidiogenesis of the Rice Blast Fungus Magnaporthe oryzae
}

\author{
Wende Liu, ${ }^{1,2}$ Shiyong Xie, ${ }^{1}$ Xinhua Zhao, ${ }^{2}$ Xin Chen, ${ }^{1}$ Wenhui Zheng, ${ }^{1}$ Guodong Lu, ${ }^{1}$ Jin-Rong Xu, and \\ Zonghua Wang ${ }^{1}$
}

${ }^{1}$ Key Laboratory of Biopesticide and Chemical Biology, Ministry of Education, Fujian Agriculture and Forestry University, Fuzhou, 350002, China; ${ }^{2}$ Department of Botany and Plant Pathology, Purdue University, West Lafayette, IN 47907, U.S.A.

Submitted 24 June 2009. Accepted 9 December 2009.

\begin{abstract}
Magnaporthe oryzae starts its infection by the attachment of pyriform conidia on rice tissues, and severity of the disease epidemic is proportional to the quantity of conidia produced in the rice blast lesions. However, the mechanism of conidial production is not well understood. Homeodomain proteins play critical roles in regulating various growth and developmental processes in fungi and other eukaryotes. Through targeted gene replacement, we find that deletion of HTF1, one of seven homeobox genes in the fungal genome, does not affect mycelial growth but causes total defect of conidial production. Further observation revealed that the $\Delta h t f 1$ mutant produces significantly more conidiophores, which curve slightly near the tip but could not develop sterigmata-like structures. Although the $\Delta h t f 1$ mutant fails to form conidia, it could still develop melanized appressoria from hyphal tips and infect plants. The expression level of HTF1 is significantly reduced in the $\Delta m g b 1 \mathrm{G}-\beta$ and $\Delta c p k A$ deletion mutant, and the $A C R 1$ but not $C O N 7$ gene that encodes transcription factor required for normal conidiogenesis is significantly downregulated in the $\Delta h t f 1$ mutant. These data suggest that the HTF1 gene is essential for conidiogenesis, and may be functionally related to the trimeric G-protein signaling and other transcriptional regulators that are known to be important for conidiation in M. oryzae.
\end{abstract}

The ascomycete Magnaporthe oryzae causes blast disease in economically important crops such as rice, barley, wheat, and millet and has been developed as a model system to study fungus-plant interactions (Talbot 2003; Ebbole 2007; Xu et al. $2007 \mathrm{~b}$ ). The infection process of this pathogen is initiated by the attachment of pyriform conidia to the plant surface and differentiation of appressoria. After appressorial penetration, infectious hyphae of $M$. oryzae initially grow biotrophically in infected plant tissues (Kankanala et al. 2007) but eventually cause cell death and lesion formation on a susceptible host. When environmental conditions are suitable, the fungus produces and releases more conidia from blast lesions to reinitiate the infection cycle. The severity of the rice blast disease epidemics is proportional to the quantity of spores produced in the lesions (Teng et al. 1991). Therefore, conidium production and dispersal of conidia play critical roles in the epidemiology of rice blast as well as many other plant fungal diseases.

Corresponding authors: Z. Wang; Telephone: +86-591-83790312; E-mail: zonghuaw@163.com; and J.-R. Xu; Telephone: +1-765-496-6918; E-mail: jinrong@purdue.edu

*The $\boldsymbol{e}$-Xtra logo stands for "electronic extra" and indicates that Figure 6 appears in color online
In the model filamentous fungus Aspergillus nidulans, several transcription factors regulating different developmental stages of conidiation have been characterized, including BrlA, StuA, MedA, and AbaA (Yu et al. 2006). However, the regulatory network controlling conidiation appears to be different in another model filamentous fungus, Neurospora crassa. The StuA homolog in $N$. crassa, ASM-1, is involved in ascospore development but dispensable for asexual reproduction (Aramayo and Metzenberg 1996). In M. oryzae, disruption of the ACRl gene that encodes a protein with limited homology to MedA results in the production of head-to-tail (acropetal) arrays of elongated conidia. The ACR 1 gene seems to be a stage-specific negative regulator that is required to establish a sympodial pattern of conidiation (Nishimura et al. 2000). Another transcription factor gene that may be involved in regulating conidiation in $M$. oryzae is CON7. The $\Delta$ con 7 mutant produces conidia with abnormal cell shape and is reduced in sporulation by approximately $35 \%$ compared with that of the wildtype strain (Shi et al. 1998). Deletion of CON7 affected the expression of several genes that are important for plant infection (Odenbach et al. 2007).

In eukaryotic cells, homeobox genes encode transcription factors with the homeodomain for recognizing and binding to specific DNA sequences. The homeodomain proteins or homeoproteins are evolutionarily conserved and play regulatory roles during different developmental stages in plants, animals, and fungi (Gehring and Hiromi 1986; Scott et al. 1989; Svingen and Tonissen 2006). In fungi, homeoproteins are best studied in the budding yeast Saccharomyces cerevisiae, which has nine homeobox genes. Two of them, $H M L \alpha 2$ and $H M R \alpha 1$, are not expressed. Among the other expressed homeobox genes, $M A T \alpha 2$ and MAT $\alpha 1$ are part of the mating type locus. Mat $\alpha 2 p$ acts with the MADS-box transcription factor Mcm1p to suppress $\alpha$-specific genes in haploid cells and binds with Matalp to repress haploid-specific genes in diploid cells (Houston et al. 2002). Like $M A T \alpha 2$ and $M A T \alpha 1$, the other five yeast homeobox genes, YOX1, YHP1, TOS8, CUP9, and PHO2, are not essential for growth. Yox 1p and Yhp1p are two transcriptional repressors that interact with Mcm1p and bind to the promoters of some cell-cycle-regulated genes expressed in M/G1 phase (Kunoh et al. 2000). Yhp1p also negatively regulates the transcription of the IME1 gene that is required for the initiation of meiosis (Pramila et al. 2002). Tos8, a Swi4-Swi6 cell cycle binding factor (SBF)-regulated transcription factor, plays a role in transcriptional regulation of genes that are functional in the G1/S phase events, such as bud site selection, bud emergence, and cell cycle progression (Horak et al. 2002). CUP9 is a repressor of PTR2 (Xia et al. 2008), which encodes a major peptide transporter. $\mathrm{Pho} 2 \mathrm{p}$ interacts with Pho4p to regulate genes involved in phos- 
phate metabolism. It also binds cooperatively with Swi5 to activate Ho (a homothallic switching endonuclease) and interacts with coregulator protein Bas1 to activate genes related to purine and histidine biosynthesis (Bhoite et al. 2002).

In Schizosaccharomyces pombe and Candida albicans, the mating locus also contains homeoproteins. In addition to mating, the interaction between $C$. albicans Mtla1p and Mtl $\alpha 2 p$ homeoproteins is important for the white-opaque switching and virulence (Miller and Johnson 2002; Lockhart et al. 2005). Another homeobox gene in C. albicans is FIL2, a regulator of filamentation (Xu et al. 2007a). In Yarrowia lipolytica, the Hoylp homeoprotein also is required for hyphal formation (TorresGuzman and Dominguez 1997). Like the ascomycetous yeasts, many basidiomycetes contain homeobox genes in their mating type loci. In Ustilago maydis, the bE and bW homeobox genes are important for mating, filamentous growth, and pathogenesis (Bakkeren et al. 2008). Interestingly, the homeoproteins of the mating type locus are insufficient to regulate sexual differentiation in Cryptococcus neoformans. Two homeobox genes SXII and $S X I 2 a$ that are unlinked to the mating type locus have been shown to be required for determining cell identity and regulating sexual differentiation (Hull et al. 2005).

The first homeobox gene characterized in filamentous ascomycetes is pahl in Podospora anserina (Arnaise et al. 2001). Deletion of the pahl gene increased the production of microconidia (male gametes), indicating that it may function as a repressor of genes involved in microconidiation. The pahl deletion mutant had a reduced growth rate and formed colonies with a wavy appearance. Vegetative hyphae of the pahl mutant branched more frequently than those of the wild type (Arnaise et al. 2001). In N. crassa, mutants in which the pahl homolog $K A L-1$ was deleted were generated in a high-throughput functional genomics project (Colot et al. 2006). The kal-1 deletion mutant also had colony morphology defects and produced shorter aerial hyphae and fewer conidia. Hyphal branching was increased in the kall-1 mutant but its growth rate was reduced only when incubated at temperatures higher than $25^{\circ} \mathrm{C}$. Interestingly, the growth and conidiation defects of the kall-1 mutant can be partially restored by $2 \%$ yeast extract, indicating a possible role of $K A L-1$ in nutrient sensing. Two other $N$. crassa homeobox genes, $B E K-1$ and NCU03070, were characterized in the study (Colot et al. 2006). Although the function of NCU03070 was not described, BEK-1 (NCU00097) was required for normal development of perithecial beaks during sexual development in N. crassa (Colot et al. 2006; Krystofova and Borkovich 2006).

The $M$. oryzae genome has seven predicted homeobox genes. One of them is PTH12 that has been reported to be important for plant infection (Sweigard et al. 1998). Through deletion of the other six homeobox genes, we found, in this study, that the $\Delta h t f l$ mutant had normal colony morphology and produced abundant conidiophores but was blocked in conidium formation. Appressoria formed by hyphal tips of the $\Delta h t f l$ mutant were able to penetrate and infect plant cells. Our data indicated that the $H T F 1$ gene may specifically regulate the differentiation of conidia. Moreover, gene expression analysis suggested that Htf1 may be functionally regulated through the trimeric G-protein signaling pathway and other transcriptional regulators such as Acr1 and Con7 that are known to be important for conidiation in M. oryzae.

\section{RESULTS}

\section{Homeobox genes in M. oryzae.}

The $M$. oryzae genome has seven predicted genes encoding proteins with the homeodomain. They are MGG_00184, MGG_01730, MGG_04853, MGG_06285, MGG_07437,
MGG_11712, and MGG_12865 (Fig. 1A). The last one is the PTH12 gene that was disrupted in one of the insertional mutants with reduced virulence (Sweigard et al. 1998). The Mst12 (MGG_12958) gene was originally regarded to have a homeobox domain (residues 61 to 205) (Park et al. 2002) but this region is considered to be an STE-like transcription factor domain rather than homeodomain in the fungal genome annotation. Therefore, we characterized the other six homeobox genes, designated herein as $\mathrm{Htf1}$ to $\mathrm{Htf6}$ (for homeodomain transcription factor genes).

The position of the homeodomain varies among these homeobox genes (Fig. 1A). In Htf1, Htf2, Htf3, and Htf6, the homeodomain is near the $\mathrm{N}$-terminous regions. It is in the central region of Htf5 and C-terminal regions of Htf4 and Pth12 (Fig. 1A). The homology among these seven homeobox genes in $M$. oryzae is limited to the homeodomain that is responsible for DNA binding. Sequence alignment (Fig. 1B) and phylogenetic analysis (Fig. 1C) with the homeodomain sequences revealed that these homeobox genes could be divided into three subgroups. Htf2, Htf4, and Pth12 formed one clade, and Htf3, $\mathrm{Htf} 5$, and Htf6 were in another one. The homeodomain of $\mathrm{Htf} 1$ appeared to be more distantly related to that of the other homeobox genes (Fig. 1C).

\section{HTF1 is dispensable for vegetative growth but essential for conidiation.}

To determine the function of these predicted homeobox genes in $M$. oryzae, we generated targeted deletion mutants by gene replacement approach (Table 1; Fig. 2A). Mutants with gene deletion were selected on hygromycin-containing me-

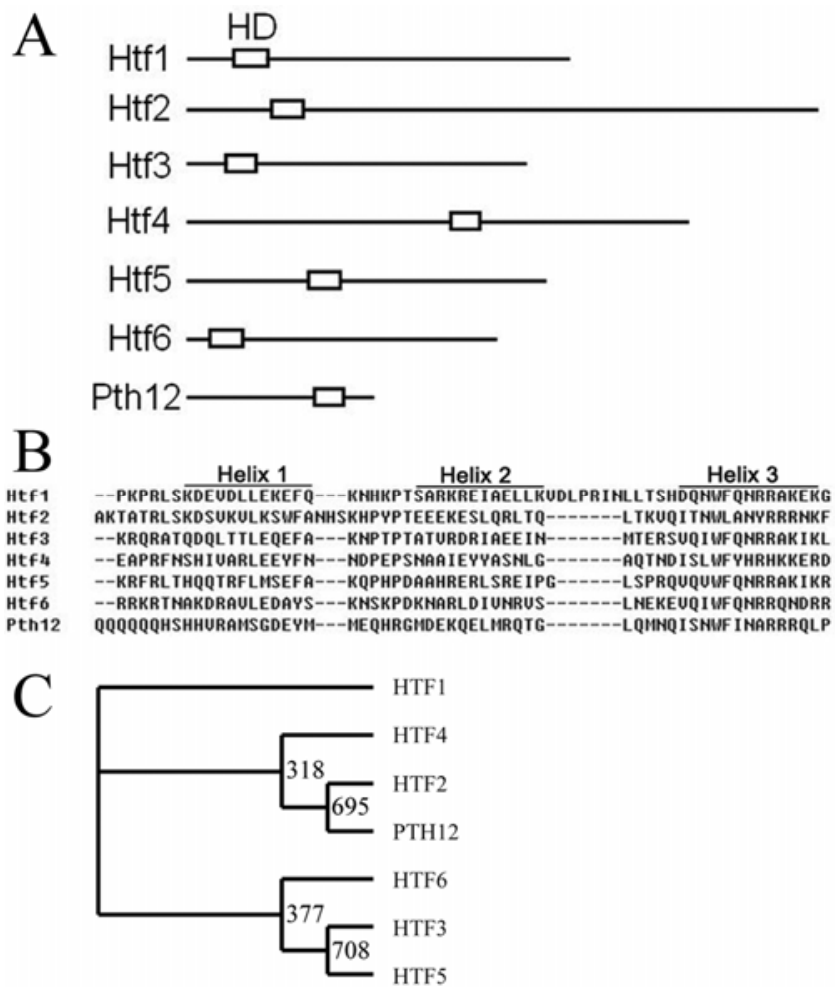

Fig. 1. Homeobox genes in Magnaporthe oryzae. A, Schematic diagram of seven predicted homeobox genes: HTF1 (MGG_00184), HTF2 (MGG_ 01730), HTF3 (MGG_04853), HTF4 (MGG_06285), HTF5 (MGG_07437), HTF6 (MGG_11712), and PTH12 (MGG_12865). Empty box, homeodomain (HD). B, Sequence alignment of the homeodomains. Three predicted helixes labeled on the top. C, Phylogenetic analysis with the homeodomain sequences of seven homeobox genes. A bootstrapped analysis was performed with 1,000 iterations and bootstrap value were indicated on the branches. 
dium and then confirmed by polymerase chain reaction (PCR) and Southern blot analyses (Fig. 2B). When cultured on complete medium (CM) and oatmeal agar plates, the $\Delta$ htfl mutants had no obvious difference in vegetative growth in comparison with the wild-type strain Guy11 (Fig. 3A; Table 2); however, the $\Delta h t f 1$ mutants failed to form conidia (Table 2, HK11 and HK12).

Although the $\Delta h t f l$ mutant was blocked in conidiation, it still formed grayish colonies (Fig. 3A). Examination by light microscopy of the aerial cultures stained with lactophenol cotton blue revealed that $\Delta h t f l$ mutant developed conidiophore stalks very well (Fig. 3B). This result was consistent with the observation from scanning electron microscopy, showing that only conidiophores but no conidia existed in the culture of the $\Delta$ htfl mutants.

When the $\Delta h t f l$ mutant was examined under a dissecting microscope, abundant conidiophores were observed. However, unlike the wild-type strain, conidiophores of the $\Delta h t f l$ mutant failed to differentiate conidia (Fig. 4A). We also examined colonies formed by the $\Delta h t f l$ mutant by scanning electron microscopy (SEM). In comparison with the wild-type strain, conidiophores of the $\Delta h t f 1$ mutant had no conidia and did not display the typical sympodial (zigzag) pattern (Fig. 4B). However, tips of $\Delta h t f l$ conidiophores were often curved to various

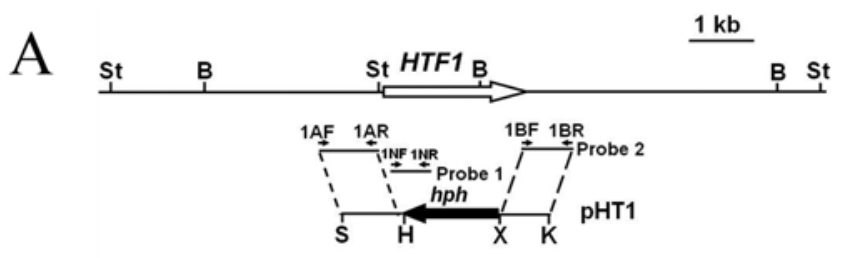

B
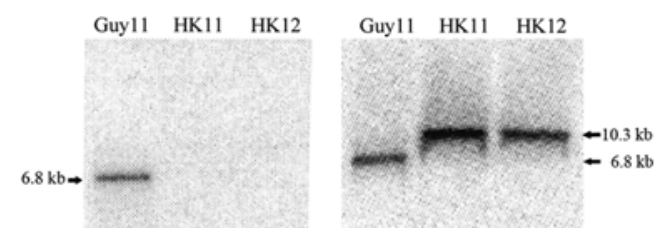

Fig. 2. Generation of $H T F 1$ mutants. A, $H T F 1$ gene replacement construct was constructed by amplifying the upstream and downstream flanking sequences with primers $1 \mathrm{AF} / 1 \mathrm{AR}$ and $1 \mathrm{BF} / 1 \mathrm{BR}$ and ligated with the $h p h$ cassette. Probe is fragments amplified by polymerase chain reaction with primers 1NF/1NR. Restriction enzymes were as follows: B, BamHI; H, HindIII; K, KpnI; S, SacI; St, StuI; X, XhoI. B, DNA gel blot analysis of genomic DNA from Guy 11 and 2 transformants digested with StuI using the radiolabeled probes as shown in A. The results show a single $6.8-\mathrm{kb}$ band for the wild type (Guy11) and no band for gene replacement (HK11, andHK12) when using probe1 (left); and a single 6.8-kb band for the wildtype (Guy11) and another single $10.3-\mathrm{kb}$ band for gene replacement (HK11 and HK12) when using probe 2 (right). degrees. Unlike sympodial conidiophores formed by the wildtype strain, curving conidiophores of the $\Delta h t f l$ mutant had a smooth appearance and lacked sterigmata-like structures (Fig. 4B). These results indicate that the $\Delta h t f l$ mutant was not defective in conidiophore development but was blocked in subsequent conidiogenesis (differentiation of sterigmata and conidium formation).

When mated with the wild-type strain $70-15$, the $\Delta h t f l$ mutant produced fertile perithecia, suggesting that HTFl is not required for the fungal sexual reproduction. We then isolated 32 ascospore progeny from this cross. All 19 hygromy-
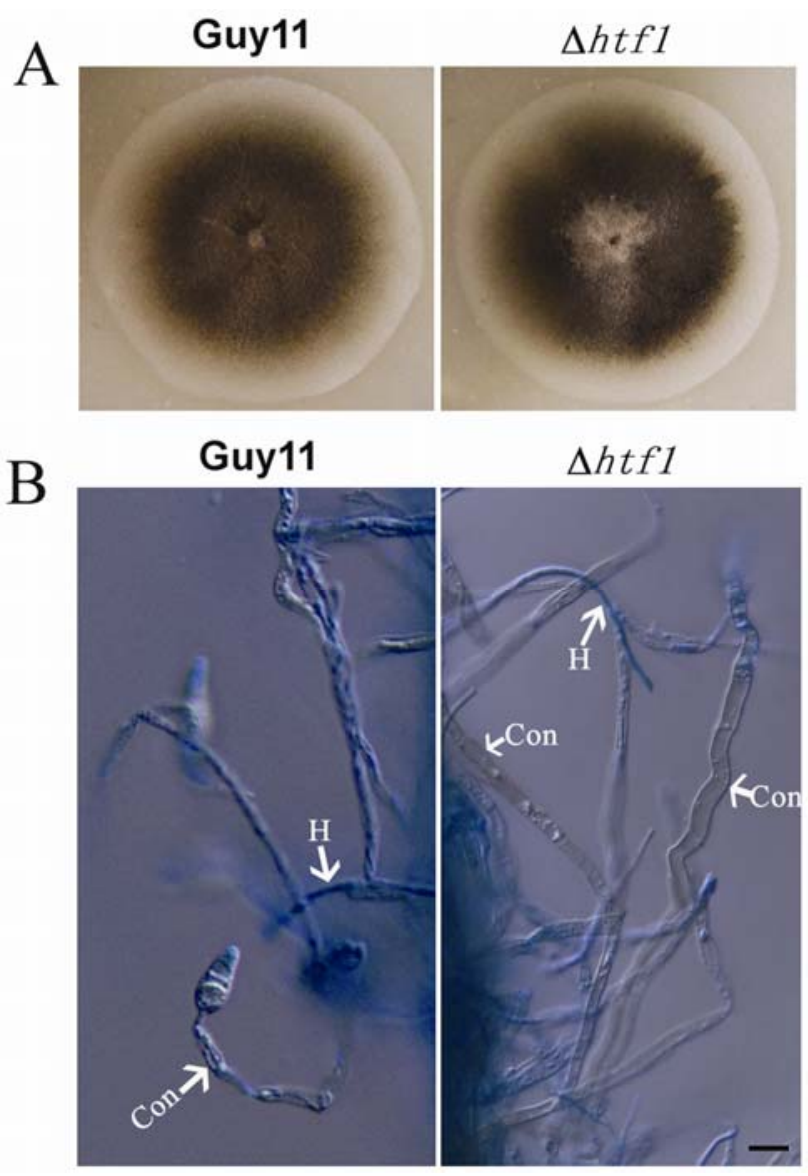

Fig. 3. Colony morphology and lactophenol cotton blue staining of the wild type and the $\Delta h t f 1$ mutant strains. A, Colony morphology of wildtype Guy11 and the HTF1 mutant grown on oatmeal agar plates for 10 days. B, Aerial cultures stained with lactophenol cotton blue observed under a light microscope. Hyphae are stained blue, whereas conidiophore stalks are in gray. $\mathrm{Bar}=20 \mu \mathrm{m}$. Con, conidiophores; $\mathrm{H}$, hyphae.

Table 1. Wild-type and mutant strains of Magnaporthe oryzae used in this study

\begin{tabular}{|c|c|c|}
\hline Strain & Brief description & Reference \\
\hline Guy11 & Wild type, MAT1-2 & Chao and Ellingboe 1991 \\
\hline $70-15$ & Wild type, MAT1-1 & Chao and Ellingboe 1991 \\
\hline nn78 & $\Delta p m k 1$ mutant of Guy 11 & Xu and Hamer 1996 \\
\hline nw96 & $\Delta m g b 1$ mutant of Guy11 & Nishimura et al. 2003 \\
\hline $\mathrm{I} 27$ & $\Delta c p k A$ mutant of Guy11 & Mitchell and Dean 1995 \\
\hline HK11 & Dhtfl (MGG_00184) mutant of Guy11 & This study \\
\hline HK12 & $\Delta h t f 1$ mutant of Guy11 & This study \\
\hline HE1 & Ectopic transformant of the $H T F 1$ knockout construct & This study \\
\hline $\mathrm{HC} 1$ & HK11 transformed with pYH1 (wild-type $H T F 1$ ) & This study \\
\hline HD12 & $H T F 1^{\triangle \mathrm{HD}}$ in $\mathrm{HK} 11$ & This study \\
\hline HD14 & $H T F 1^{\Delta \mathrm{HD}}$ in $\mathrm{HK} 11$ & This study \\
\hline HD15 & $H T F 1^{\Delta \mathrm{HD}}$ in $\mathrm{HK} 11$ & This study \\
\hline HD17 & $H T F 1^{\triangle \mathrm{HD}}$ in $\mathrm{HK} 11$ & This study \\
\hline N184-12 & HK11 transformed with the $H T F 1$-EGFP construct & This study \\
\hline
\end{tabular}


cin-resistant progeny failed to produce conidia but the 13 hygromycin-sensitive progeny were normal in conidium production, suggesting that there is only one gene locus inserted with the $H P H$ gene. We also cloned the entire $H T F 1$ gene to complement the $\Delta h t f 1$. Transformants of the $\Delta h t f 1$ mutant expressing the wild-type $H T F 1$ allele restored the ability to conidiate normally (Table 2, HC1). Therefore, deletion of $H T F 1$ was directly responsible for the defects observed in the $\Delta$ htfl mutant.

\section{The $\Delta h t f 1$ mutant could still develop}

\section{functional appressoria from hyphal tips.}

In $M$. oryzae, appressorium formation is normally assayed with conidia on hydrophobic surfaces. Because the $\Delta h t f 1 \mathrm{mu}-$ tant did not produce conidia, we assayed appressorium formation by hyphal tips by inserting plastic coverslips in front of the edge of fungal colonies. After incubation for $48 \mathrm{~h}$, melanized appressoria were formed by approximately $10 \%$ of the hyphal tips examined in both the wild-type and $\Delta h t f 1$ mutant strains (Fig. 5A). Some hyphae developed swollen or deformed tips, which likely represent early stages of appressorium formation. We also examined appressorium formation on rice leaves with a similar approach. Abundant appressoria were observed in both the $\Delta$ htfl mutant and wild type Guy11 (Fig. 5B). These appressoria formed by hyphal tips were melanized and morphologically similar to those formed by germ tubes of Guy11 conidia. These results indicated that the HTF1 gene is required for conidiation but dispensable for appressorium formation.

Table 2. Growth rate and conidiation by Magnaporthe oryzae strains ${ }^{\mathrm{a}}$

\begin{tabular}{lccc}
\hline Strain & $\begin{array}{c}\text { Growth rate } \\
(\mathbf{m m} / \mathbf{d a y})^{\mathbf{b}}\end{array}$ & $\begin{array}{c}\text { Conidiation }\left(\times \mathbf{1 0}^{\mathbf{5}}\right. \\
{\text { conidia/plate })^{\mathbf{c}}}^{\mathbf{2}}\end{array}$ & $\begin{array}{c}\text { Conidiophores per } \\
\text { microscope field }^{-}\end{array}$ \\
\hline Guy11 & $5.63 \pm 0.06$ & $47.60 \pm 9.28$ & $11.10 \pm 2.05$ \\
HK11 & $5.60 \pm 0.20$ & 0 & $39.27 \pm 1.27$ \\
HK12 & $5.70 \pm 0.10$ & 0 & $39.87 \pm 2.96$ \\
HE1 & $5.47 \pm 0.12$ & $49.90 \pm 6.64$ & ND \\
HC1 & $5.70 \pm 0.10$ & $42.60 \pm 12.15$ & ND \\
HD17 & $5.67 \pm 0.15$ & 0 & ND \\
\hline
\end{tabular}

${ }^{\mathrm{a}}$ Mean and standard deviations were calculated from three independent experiments; $\mathrm{ND}=$ no data.

${ }^{\mathrm{b}}$ Colony diameter $(\mathrm{mm})$ was measured after incubating for 5 days at $25^{\circ} \mathrm{C}$.

${ }^{\mathrm{c}}$ Number of conidia formed on each oatmeal agar plate (diameter $9 \mathrm{~cm}$ ) examined after incubation for 14 days

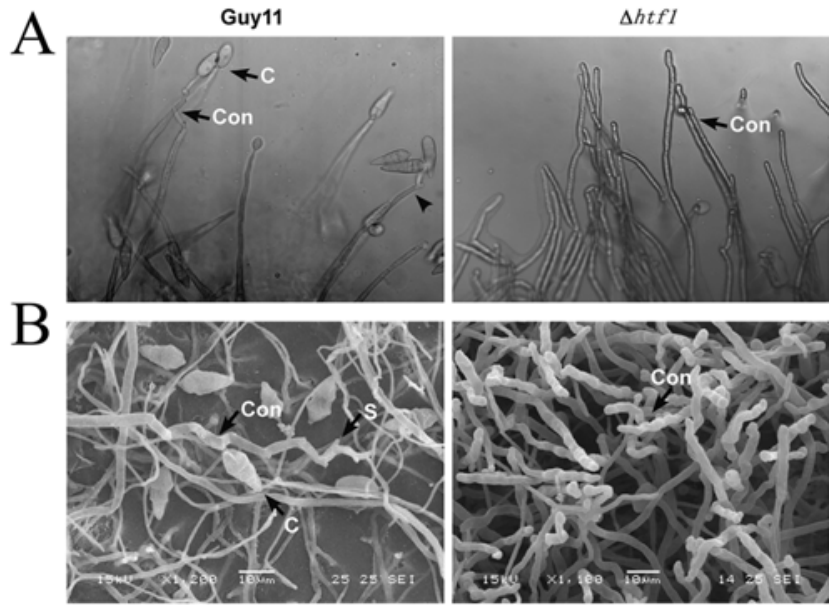

Fig. 4. Examination for conidiation in the wild-type and $\Delta h t f l$ mutant strains. A, Images of 10-day old cultures examined under a dissecting microscope and $\mathbf{B}$, by scanning electronic microscopy. Arrows point to conidiophores (Con), conidia (C), and sterigmata (S).
Appressoria formed by the $\Delta h t f 1$ mutant were normal in plant penetration and infection.

To further assay whether appressoria formed by the $\Delta h t f l$ mutant were able to penetrate plant cells, we conducted onion epidermal cell penetration assays with blocks of mycelia. After incubation at room temperature for $36 \mathrm{~h}$, agar blocks were removed. Appressorium formation was examined after another $24 \mathrm{~h}$. Hyphal tips of the $\Delta h t f l$ mutant formed melanized appressoria that could penetrate onion epidermal cells and formed normal infectious hyphae (Fig. 6A). No obvious difference was observed between the $\Delta h t f l$ mutant and Guy11 in appressorium formation and plant penetration by hyphal tips.

We also conducted infection assays with blocks of mycelium from oatmeal agar cultures. On rice and barley leaves inoculated with Guy11 and the $\Delta h t f 1$ mutant, blast lesions were observed at the inoculation sites 7 days postinoculation (dpi) (Fig. 6B). The $\Delta h t f l$ mutant also was pathogenic in infection assays with rice roots (Fig. 6B). When rice leaf segments with blast lesions were excised and incubated on water agar after surface sterilization, conidia and conidiophores were formed on leaves infected by the wild-type strain after incubation for 3 days in a moisture chamber at $25^{\circ} \mathrm{C}$. Under the same conditions, only conidiophores were observed on the lesions caused by the $\Delta h t f 1$ mutant (Fig. 6C), indicating that HTF1 is also required for conidiation on the host plant. Although it is dispensable for plant infection under laboratory conditions, the HTF 1 gene regulates a critical step in the disease cycle of $M$. oryzae.

The homeodomain is essential for the function of HTF1.

The homeodomain is the only conserved motif that was identified in the $\mathrm{Htf} 1$ protein. To determine its function, we generated the $H T F 1^{\triangle \mathrm{HD}}$ allele, deleting residues 86 to 146 , and transformed it into the $\Delta h t f l$ mutant (Fig. 7A). Six transformants, including HD12 and HD14 (Table 1), were confirmed by Southern analyses to contain the $H T F 1^{\triangle \mathrm{HD}}$ construct in the genome (data not shown). The expression of the $H T F 1^{\triangle \mathrm{HD}}$ construct in transformant HD12 and HD14 was verified by reverse-transcription (RT)-PCR (Fig. 7B). Similar to the $\Delta$ htfl mutant, HD17 (Table 2) and other HTF ${ }^{\triangle \mathrm{HD}}$ transformants produced conidiophores but not conidia on rice polish and oat-

A
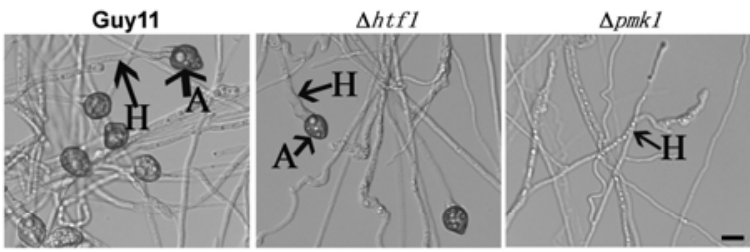

$\mathrm{B}$
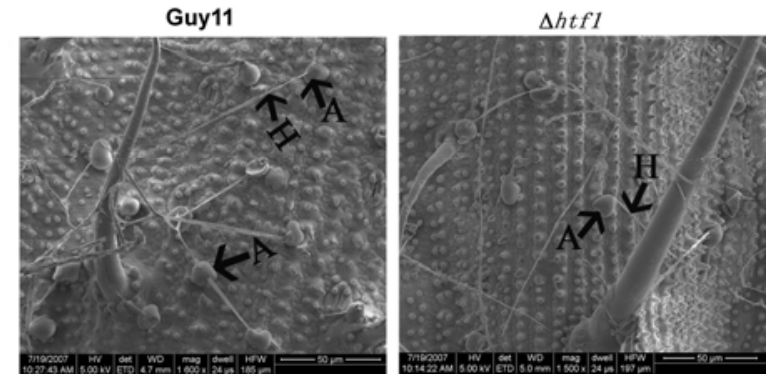

Fig. 5. Appressorium formation assays with the $\Delta$ htfl mutant. A, Appressoria formed on plastic cover slips by hyphal tips of Guy11 and the $\Delta h t f 1$ mutant; hyphal tips of the $\Delta p m k 1$ mutant failed to form appressoria as a control. B, Appressoria formed on rice leaf surface by hyphal tips of Guy11 and the $\Delta h t f 1$ mutant. Bar $=10 \mu \mathrm{m}$. Arrows point to hypha $(\mathrm{H})$ and appressorium (A). 
meal agar media (Fig. 7C). On barley or leaves inoculated with mycelia of transformants expressing the $H T F 1^{\triangle \mathrm{HD}}$ allele, blast lesions were observed after 7 dpi (data not shown). However, these lesions failed to produce any conidia after incubation on water agar for $48 \mathrm{~h}$ (data not shown). Thus, we conclude that deletion of the homeodomain abolished the function of the $H T F 1^{\triangle \mathrm{HD}}$ allele.

\section{Expression of the Htf1-EGFP fusion construct.}

A Htf1-EGFP (enhanced green fluorescent protein) in-frame fusion construct under the control of its native promoter was generated and transformed into the $\Delta h t f l$ mutant. Strain N18412 (Table 1) was one of the resulting transformants that were confirmed to contain the HTF1-EGFP construct by Southern analysis. It produced normal conidia (Fig. 8), suggesting that HTF1-EGFP functionally complemented the defect of the $\Delta h t f 1$ mutant. However, GFP signals were not detectable or extremely weak in vegetative hyphae and mature conidia. Although faint fluorescent signals were observed in some of the conidiophores and developing conidia, nuclear localization of Htf1-EGFP fusion proteins was difficult to observe (Fig. 8). Considering that $\mathrm{C}$-terminal fusion might interfere with detection of GFP, we also generated an $\mathrm{N}$-terminal fusion construct (EGFP-HTFl) and transformed it into the $\Delta h t f 1$ mutant. All 10 resulting transformants produced normal conidia but the GFP signal was too weak to determine the nuclear localization of $\mathrm{Htf} 1$ protein (data not shown). It is likely that the Htf1 protein may be activated and localized to the nucleus but its nuclear localization may be too transient to be detected during conidiation in M. oryzae.

A

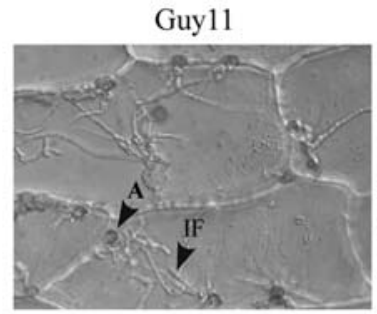

B

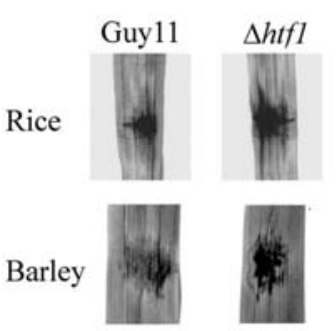

$\mathrm{C}$
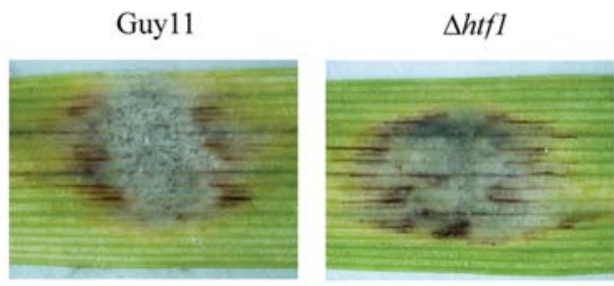

Fig. 6. Penetration and plant infection assays with mycelial blocks of the $\Delta h t f 1$ mutant. A, Penetration of onion epidermal cells by appressoria formed by hyphal tips of the wild-type and $\Delta h t f 1$ mutant strains. A, appressoria; IF, infectious hyphae. Bar $=10 \mu \mathrm{m}$. B, Lesions formed by mycelial blocks of Guy 11 and the $\Delta h t f 1$ mutant on rice and barley leaves (left) and rice roots (right). C, Lesions caused by Guy11 and the $\Delta$ htfl mutant were surface sterilized and examined for conidiation after incubating for 3 days on $2 \%$ water agar. The $\Delta h t f 1$ mutant formed conidiophores but failed to produce conidia.

\section{HTF1 is not involved in the repression} of conidium development under nonconducive conditions.

Because the $\Delta h t f l$ mutant appeared to produce more conidiophores than the wild-type strain on culture plates (Fig. 4A and B), HTF 1 may function as a negative regulator of conidiophore development. Quantification of conidiophore development showed that the $\Delta h t f 1$ mutant formed significantly $(P<0.01)$ more conidiophore than the wild-type strain Guy11 (Table 2) from the same size of oatmeal culture block under conditions with light. In cultures maintained in the dark, no obvious differences in conidiophore development were observed between the $\Delta h t f l$ mutant and Guy11 (data not shown). We then assayed conidiophore development in liquid CM cultures. Similar to Guy 11, the $\Delta h t f 1$ mutant failed to develop conidiophores in vegetative hyphae grown in liquid CM (data not shown). These data indicate that the $\Delta h t f l$ mutant is not derepressed in conidiophore development under nonconducive conditions.

The HTF 1 expression was detected at all growth stages, including conidium, mycelium, appressorium, and infectious hypha, by quantitative real-time (q)RT-PCR, with the lowest level at the conidiophore stage (Fig. 9A). To further determine whether HTF 1 expression is affected at different growing conditions, we conducted qRT-PCR with RNA samples isolated from the wild-type strain cultures on rice polish agar media or submerged cultures in liquid CM under constant light or dark conditions. Data from three independent experiments indicated that the expression level of HTF 1 was increased significantly $(P<0.01)$ in cultures under constant-dark compared with constant-light conditions. To our surprise, the expression level of HTFl was increased over 38 -fold $(P<0.01)$ more in submerged cultures in liquid CM under the constantly dark condition (Fig. 9B) than the cultures on rice polish agar medium with constant light. It is known that constant light and rice polish agar medium are conducive for conidiation in M. oryzae. Therefore, the elevated expression level of HTF1 gene in non-

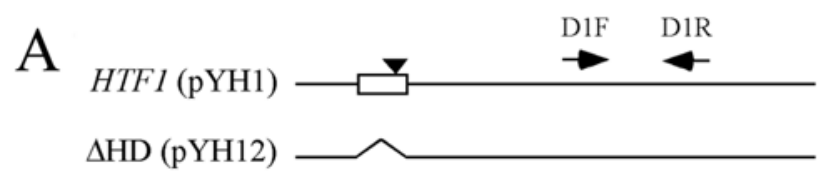

B
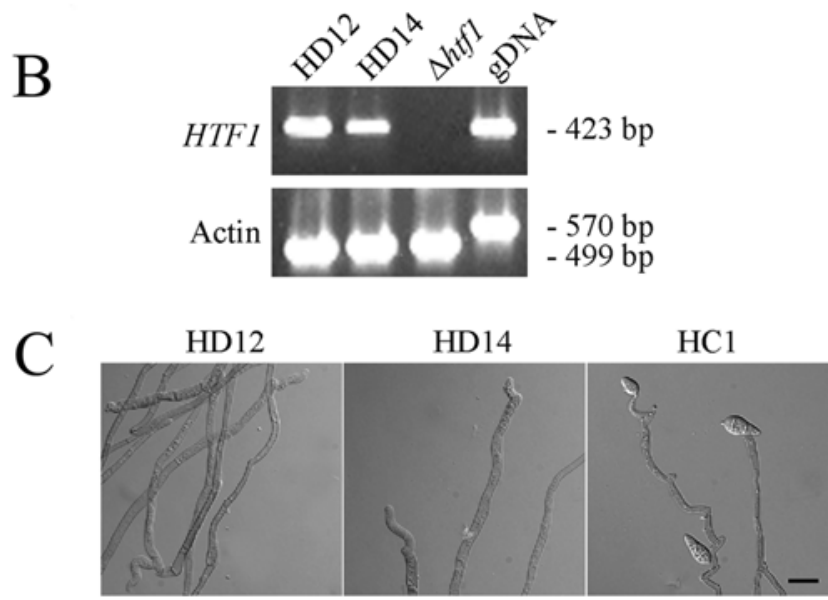

Fig. 7. Function analysis of the homeodomain of the $H T F 1$ gene. A, Diagram of the $H T F 1^{\triangle \mathrm{HD}}$ allele. The homeodomain (empty box) was deleted in pYH12. The position of the only intron of the HTF1 gene is labeled with a filled triangle. Primers D1F and D1R were used to amplify HTF1. B, Reverse-transcription polymerase chain reaction with RNA isolated from the $\Delta h t f 1$ mutant and $H T F 1^{\Delta \mathrm{HD}}$ transformants HD12 and HD14. Genomic DNA (gDNA) was used as the control. C, Conidiophores formed by the complementation strain $\mathrm{HC} 1$ and $H T F 1^{\triangle \mathrm{HD}}$ transformants HD12 and HD14. $\mathrm{Bar}=10 \mu \mathrm{m}$. 
conducive conditions might suggest that Htf1 functions as a negative regulator of the fungal conidiophore formation. Another possibility is that feedback signals from conidia may inhibit further conidiophore development through modulating the HTF1 expression in M. oryzae.

\section{The expression of $H T F 1$ was downregulated in the $\Delta m g b 1$ and $\Delta c p k A$ mutant.}

In $M$. oryzae, several genes have been implicated in regulating conidiation, including components of the trimeric G-proteins. The $\Delta m g b l$ G- $\beta$ mutant rarely produces conidia and forms fluffy colonies with abundant conidiophores (Nishimura et al. 2003). The gene encoding the catalytic subunit of the cAMPdependent protein kinase ( $\mathrm{CpkA}$ ) is a downstream component of the G-protein pathway (Fang and Dean 2000; Nishimura et al. 2003). To determine the expression level of HTF1, we conducted qRT-PCR with RNA samples isolated from aerial hyphae and conidiophores of the wild-type, $\Delta m g b l$, and $\Delta c p k A$ mutant strains grown on oatmeal agar for 10 days. Data from three independent experiments indicated that the expression level of $H T F 1$ was reduced over fivefold $(P<0.01)$ in the $\Delta m g b 1$ mutant and approximately twofold in the $\Delta c p k A$ mutant $(P<0.05)$ (Fig. 10A). Therefore, the HTF1 gene may function downstream from the trimeric G-protein signaling to regulate conidium formation in $M$. oryzae. However, the exogenous cAMP could not rescue the mutant defect in conidiation by growing the htfl mutant strain on the oatmeal agar plate with supplement of $10 \mathrm{mM} \mathrm{cAMP}$ (data not shown).

Deletion of $H T F 1$ reduced the expression of the $A C R 1$ gene.

$H T F 1$ is specifically involved in the regulation of conidiation but not conidiophore development. In $M$. oryzae, two other transcription factor genes, $A C R 1$ and $C O N 7$, are known to regulate conidiogenesis and conidium morphology (Lau and Hamer
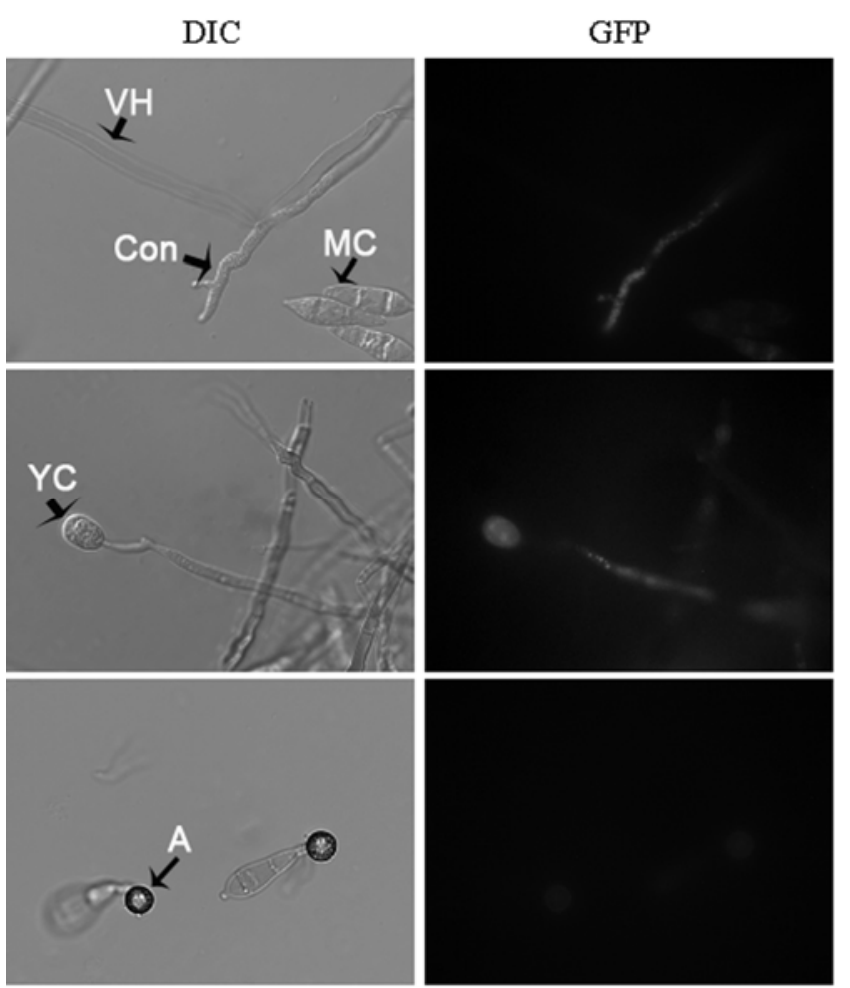

Fig. 8. Expression and localization of HTF1-EGFP (enhanced green fluorescent protein) fusion proteins. Weak GFP signals were observed in conidiophores and young developing conidia from transformants expressing the HTF1-EGFP fusion construct. A, appressoria; Con, conidiophores; $\mathrm{VH}$, vegetative hyphae; MC, mature conidia; YC, young conidia.
1998; Odenbach et al. 2007). To determine the effect of $\Delta h t f l$ mutation on ACRI and CON7, we assayed the expression of these two genes by qRT-PCR. In comparison with that of Guy11, the expression level of $A C R l$ was reduced significantly $(P<0.05)$ in the $\Delta h t f l$ mutant (Fig. 10B). However, expression of the $C O N 7$ gene was not significantly $(P>0.05)$ reduced in the $\Delta$ tff mutant (approximately $80 \%$ of the wild type). As a control, the expression level of BUFl involved in melanin synthesis but not conidiation was not affected under the same experimental conditions (Fig. 10B).

\section{DISCUSSION}

Homeodomain proteins are well conserved for regulating development and differentiation in various eukaryotic organisms. In Saccharomyces cerevisiae, four of the nine homeobox genes are related to the mating type or switching locus (Houston et al. 2002). Like many other filamentous ascomycetes, $M$. oryzae does not contain homeobox genes in the mating type loci and lacks putative homologs of yeast MAT $\alpha 2$ and MAT $\alpha 1$ (Kanamori et al. 2007). Therefore, it is rational to expect that homeobox genes may play a different but important role in the growth, development, and plant infection of the fungus. Indeed, Sweigard and associates (1998) already indicated the important role of PTH12. In this study, we demonstrated that HTF1 is a key regulator for the fungal conidiogenesis in $M$. oryzae. To our knowledge, HTFl is the only gene in M. oryzae that is known to be specifically and absolutely required for conidia-

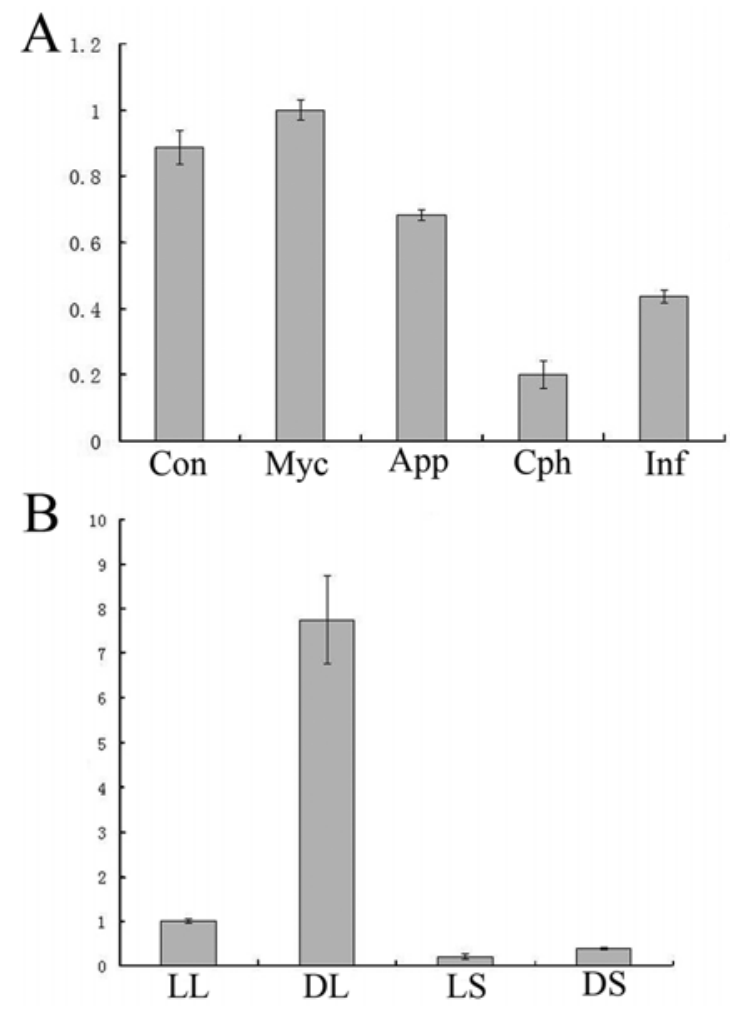

Fig. 9. Real-time reverse-transcription polymerase chain reaction quantifying HTF 1 expression at different developmental stages in Magnaporthe oryzae. A, Expression at the conidiophore stage showed the lowest level compared with conidium, mycelium, appressorium, or infectious hyphae stage. Con, conidium; Myc, mycelium; App, appressorium; Cph, conidiophore; Inf, infectious hypha. B, Expression level of HTF1 was increased significantly $(P<0.01)$ in cultures under constant dark compared with constant light condition, reaching the maximum in submerged cultures in liquid complete media under the constant dark condition. LL, light liquid; DL, dark liquid; LS, light solid; DS, dark solid. Mean and standard deviation were calculated from data of three replicates. 
tion, and also the first homeobox gene reported to be involved in conidia development in filamentous ascomycete fungi.

Interestingly, we found that deletion of $H T F 1$ blocked conidiation but not the development of conidiophores in $M$. oryzae. This is different from the role of COS1, in which gene deletion also causes defect in conidiation, but it is shown that Cos 1 is essential for conidiophore development (Zhou et al. 2009). It seems that HTF 1 may function as an essential positive regulator for switching from conidiophore growth to the initiation of conidium development. Therefore, conidiophores fail to produce conidia when HTFl is deleted. Because the $\Delta$ htfl mutant appeared to produce more abundant conidiophores than the wildtype strain under suitable conditions, $H T F 1$ may also function as a negative regulator of conidiophore development in $M$. oryzae. However, the $\Delta h t f l$ mutant did not form conidiophore-like structures in darkness or in liquid CM cultures. It is likely that $H T F 1$ does not directly regulate conidiophore formation. Increased conidiophore development in the $\Delta h t f l$ mutant may be an indirect consequence of its defects in conidium formation.

Conidiation has been best studied in A. nidulans and $N$. crassa. However, unlike $M$. oryzae, these two model filamentous fungi do not form conidia sympodially on conidiophores. In $N$. crassa, the predicted gene NCU03070.3 shared 33\% identity with HTF1 but its function was not described in the original high-throughput functional genomics study (Colot et al. 2006). The mutant deleted in NCU03070.3 (Fungal Genetics Stock Center, Kansas City, MO, U.S.A.) had no obvious changes in vegetative growth. Normal macroconidia were formed in chains on short, branched conidiophores (data not shown). These results suggest that the conidiogenesis processes are regulated by different transcription factors in $N$. crassa and $M$. oryzae. In A. nidulans, the brlA mutant forms conidiophores but rarely produces conidia (Mah and Yu 2006). The $M$. oryzae genome lacks a distinct homolog of brlA. Mutants deleted for MGG_00501, a predicted gene with limited similarity to $\mathrm{brlA}$, were reduced in conidiation but still formed normal sympodial conidiophores and pyriform conidia (S.-L.

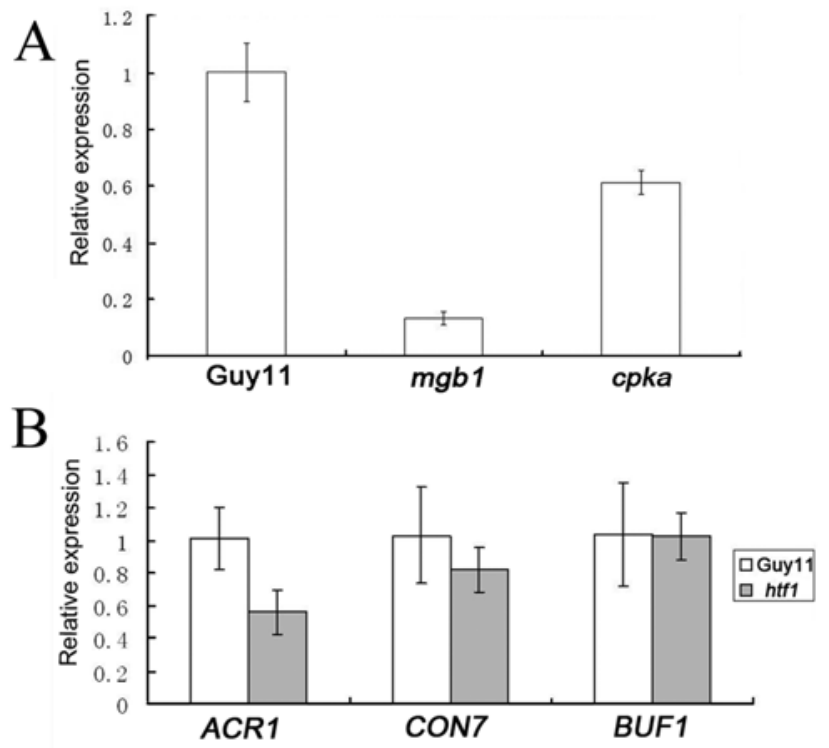

Fig. 10. Real-time reverse-transcription polymerase chain reaction analyses of the HTF1, ACR1, CON7, and BUF1 transcripts. The relative quantity of the transcripts of each gene was compared between the wild-type strain (arbitrarily set to 1) and the $\Delta m g b 1$ and $\triangle c p k a$ mutant. A, Expression level of $H T F 1$ was reduced in the $\triangle m g b 1$ and $\triangle c p k a$ mutant. $\mathbf{B}, A C R 1$ and CON7 genes but not the BUF1 gene had a reduced transcription level in the $\Delta h t f l$ mutant (filled boxes) in comparison with that of Guy11 (empty box). Mean and standard deviation were calculated from data of three replicates.
Ding and J.-R. Xu, unpublished). An08g02580 is a predicted homeobox gene that is homologous to HTF1 but has not been functionally characterized in A. nidulans.

A number of mutants that are defective in conidiation or have altered conidium morphology have been reported in $M$. oryzae, such as $\Delta a c r 1, \Delta$ con1, $\Delta$ con7, $\Delta$ MoATG8, $\Delta$ Mgracl, $\Delta m g b 1$, and $\Delta \cos 1$ (Chen et al. 2008; Deng et al. 2009; Lau and Hamer 1998; Nishimura et al. 2000; Odenbach et al. 2007; Shi et al. 1998; Zhou et al. 2009). However, most of the conidiationrelated genes characterized in $M$. oryzae are not specific or essential for conidiogenesis. In fact, many of these mutants have pleiotropic defects in other developmental or plant-infection processes. In a large-scale random insertional mutagenesis project, MGG_00184 was tagged by the transforming T-DNA (Jeon et al. 2007). The disruptant was reported to be blocked in conidiation but no further characterization of its phenotype was reported. Our efforts to characterize the homeobox genes in $M$. oryzae were initiated in 2005 . Our studies indicated that the $\Delta h t f 1$ mutant had no defects in appressorium formation. Appressoria formed by hyphal tips were able to penetrate plant cells, and the $\Delta h t f l$ mutant caused typical blast lesions on leaves inoculated with mycelial blocks. Because rice blast is a polycyclic disease, blocking conidiation can serve as an efficient disease control strategy. Therefore, it will be important to determine molecular mechanisms regulating the Htfl transcription factor and genes regulated by $H T F 1$ in $M$. oryzae. HTF1 may function downstream from $M G B 1$ because the expression level of $H T F 1$ was significantly $(P<0.01)$ reduced in the $\Delta m g b l$ mutant $(F i g$. $10 \mathrm{~A})$. Trimeric G-proteins are known to regulate conidiation in several filamentous ascomycetes, including Cochliobolus heterostrophus and A. nidulans (Ganem et al. 2004; Yu et al. 2006). In $M$. oryzae, the cAMP-protein kinase A (PKA) pathway functions downstream of the trimeric G-proteins (Fang and Dean 2000; Nishimura et al. 2003). The Htf1 protein has two putative PKA phosphorylation sites outside the homeodomain but their role in its activation is not clear.

The homeodomain of HTF1 is essential for its function. By searching the homeodomain resource database, we found that the homeodomain of HTF1 shared limited homology with that of the OTX2 gene, which has the recognition site CCTAAT CCTGGGTTATC (Briata et al. 1999). The promoter region of the $A C R l$ gene has the CCTAATCGGCGGTTTTC sequence ( -901 to -885 , identical sequences underlined) that may function as the Htf1 binding site. Our qRT-PCR data indicated that the expression level of $A C R I$ was reduced approximately twofold in the $\Delta h t f 1$ mutant (Fig. 10B). The CON7 gene lacks a similar site in the promoter region, and its transcription level was not reduced significantly in the $\Delta h t f l$ mutant (Fig. 10B). Further studies are necessary to determine the actual binding site of the homeodomain of Htfl and the relationship among conidiation-related transcription factors in $M$. oryzae. Some

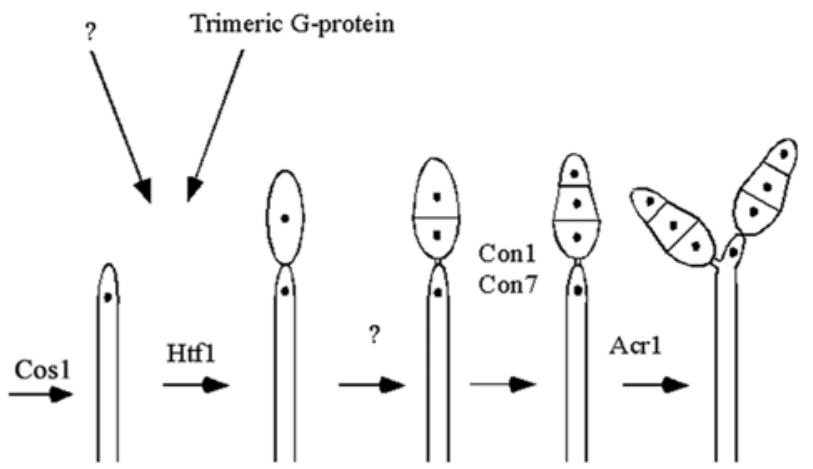

Fig. 11. Model scheme for the role of $\mathrm{Htf} 1$ in conidiogenesis. 
homeoproteins are known to exert regulatory roles via combinatorial interaction with other transcription factors (Bhoite et al. 2002). In M. oryzae, Htf1 may interact with Acr1 or other transcription factors during conidiogenesis.

Taken together, we proposed a model to interpret how $\mathrm{Htf} 1$ might regulate conidiation (Fig. 11). Conidiation is stimulated by light and inhibited in submerged cultures in M. oryzae. Young conidia formed at the tip of conidiophores are single celled. Mature conidia have three conidial cells that are formed by two asymmetric mitotic divisions. When the first conidium matures, the active apical tip moves to the side to produce the next conidium. This process is repeated to give rise to multiple conidia borne sympodially on conidiophores. Trimeric G-protein signaling is involved in regulating conidiophore development and conidium formation. Recently, Zhou and associates (2009) showed that Cos1 may be a key transcriptional regulator controlling genes responsible for conidiation but it is essential for conidiophore stalk development. We have demonstrated that $\mathrm{Htf1}$ is a positive regulator required for the differentiation of conidia and may also function as a negative regulator of conidiophore development. Trimeric G-proteins may function upstream from Htf1 but other mechanisms must exist to activate $\mathrm{Htf1}$ because the $\Delta m a g B(\mathrm{G} \alpha)$ and $\Delta m g b l(\mathrm{G} \beta)$ deletion mutants occasionally form rare conidia. Con 7 and Con 1 are required for normal conidium morphology and are functional in the maturation of conidia. Acr1 is required for the termination of further development in mature conidia and formation of individual conidia sympodially on conidiophores.

\section{MATERIALS AND METHODS}

\section{Culture conditions.}

The wild-type strains Guy11 and 70-15, $\Delta p m k 1$ (Xu and Hamer 1996) and $\Delta m g b l$ (Nishimura et al. 2003) mutants, and all the transformants (Table 1) generated in this study were cultured on oatmeal agar, $\mathrm{CM}$, or rice polish medium plates at $25^{\circ} \mathrm{C}$ as described (Park et al. 2006; Zhao et al. 2005). Media were supplemented with hygromycin B (Calbiochem, La Jolla, CA, U.S.A.) at $250 \mu \mathrm{g} / \mathrm{ml}$ or zeocin (Invitrogen, Carlsbad, CA, U.S.A.) at $200 \mu \mathrm{g} / \mathrm{ml}$ for selecting hygromycin-resistant and zeocin-resistant transformants, respectively. Monoconidial culture isolation, genetic crosses, and measurements of conidiation and growth rate were performed as previously described (Park et al. 2006; Zhao et al. 2005). For appressorium formation from hyphal tips, plastic coverslips were inserted in front of the edge of fungal colonies, and the coverslips were examined with a Nikon Eclipse 800 Epifluorescence microscope after $48 \mathrm{~h}$ of incubation.

\section{Quantification of conidiophores.}

When the fungus grew for 5 days on the oatmeal agar plate, the mycelia were pushed down with a glass slide. The oatmeal culture blocks $\left(4 \mathrm{~mm}^{2}\right)$ were sliced out from the edge of colonies and then placed onto a glass slide. The slides were put onto a moisture plastid plate, then incubated in a chamber with constant-light conditions for $48 \mathrm{~h}$. Conidiophores were then examined with a Nikon SMZ1000 dissecting microscope by counting 10 microscope fields for each sample. Three samples were examined for the $\Delta h t f l$ mutant and the wild-type Guy11, respectively.

\section{Statistical analysis.}

Statistical analysis was performed with the data from three replicates. Mean and standard deviation were calculated using SPSS V13.0, and one-way analysis of variance was performed on the data for significant differences between genotypes.

\section{Plant infection assays.}

Two-week-old seedlings of rice cv. CO39 and 10-day-old seedlings of barley cv. Golden Promise were used for plant

Table 3. Polymerase chain reaction primers used in this study

\begin{tabular}{|c|c|}
\hline Name & Sequence $\left(5^{\prime} \rightarrow 3^{\prime}\right)$ \\
\hline $1 \mathrm{AF}$ & CGGAGCTCCCCAGCTATGGTCAAATCA \\
\hline $1 \mathrm{AR}$ & CCCAAGCTTCCTTCTATCTCCTTGGTCGT \\
\hline $1 \mathrm{BF}$ & CCGCTCGAGGCAGTCAAGCACATACAT \\
\hline $1 \mathrm{BR}$ & GGGGTACCACCAAATGCTCGCTCACTA \\
\hline $1 \mathrm{NF}$ & GCTACTTCGTCCCTCAGTA \\
\hline $1 \mathrm{NR}$ & CCATCGCTACCTTCTCCAT \\
\hline $1 \mathrm{DB}$ & TTGGACGCTCTAGGGATGCC \\
\hline H853 & ACAGACGTCGCGGTGAGTT \\
\hline $1 \mathrm{H} 1 \mathrm{~F}$ & CCGCTCGAGTCCCGGCTGGCTTCATTG \\
\hline $1 \mathrm{H} 1 \mathrm{R}$ & GGACTAGTCTGGTCCTGCTTCGACGTTG \\
\hline $1 \mathrm{H} 2 \mathrm{~F}$ & GGACTAGTGGAATCAAAAAGACGCAAG \\
\hline $1 \mathrm{H} 2 \mathrm{R}$ & GCTCTAGAAGGACCTAATAAAGCACGAC \\
\hline $\mathrm{D} 1 \mathrm{~F}$ & TGTCACCACCGACTCCTT \\
\hline D1R & TGTTCTCCCTGGTTCCCT \\
\hline 1NGF & CGACTCACTATAGGGCGAATTGGGTACTCAAATTGGCTCGAACACCAAGAAGTGA \\
\hline 1NGR & CACCACCCCGGTGAACAGCTCCTCGCCCTTGCTCACCTTCTCGACACCTGTGTT \\
\hline BTF & TCCGTGGAAAGGTTTCCATG \\
\hline BTR & ATCCACTCGACGAAGTACGA \\
\hline $1 \mathrm{QF}$ & GGAGAAGGTAGCGATGGTGAA \\
\hline $1 \mathrm{QR}$ & GGTGTGGCTGTTGGTCGTAG \\
\hline $\mathrm{AQF}$ & GGACCAGTCGGAACAAGAGTG \\
\hline $\mathrm{AQR}$ & GACCCAAACGAGACGCAAA \\
\hline $\mathrm{BQF}$ & TGAGGAATTTGACCGTGTCTTTAC \\
\hline$B Q R$ & AATCAGGCGACCACCAATCT \\
\hline $\mathrm{CQF}$ & TCATAGTGGCAGCAGTGGAG \\
\hline CQR & CGGTTGGGCATAGAGGTTG \\
\hline $1612 \mathrm{PF}$ & CGGAGCTCGGATTGACAACGACCATT \\
\hline $1612 \mathrm{PR}$ & TCCCCGCGGGCTTTTTTTGCTGTCGCTTG \\
\hline GFP 717F & TCCCCGCGGATGGTGAGCAAGGGCGA \\
\hline GFP 717R & GCTCTAGACTTGTACAGCTCGTCCAT \\
\hline $3175 \mathrm{OF}$ & GCTCTAGAATGGACTACATGAACATG \\
\hline 3175 OR & CCGCTCGAGGGAATAGCAGGTCTTTAGTG \\
\hline
\end{tabular}


infection assays as described (Park et al. 2004). Rice root infection assays were carried out as described in Dufresne and Osbourn (2001). For infection assays with mycelial blocks of oatmeal agar, rice and barley seedlings were removed from pots and laid over a moist Whatman no. 1 filter paper with the adaxial surface of the second leaf exposed. Another layer of moist filter paper was used to cover the root areas to keep plants in position and maintain moisture. Blocks $\left(4 \mathrm{~mm}^{2}\right)$ of mycelia were excised from the edge of fungal colonies and placed over the second leaf of each plant. After incubating for $48 \mathrm{~h}$ in a moisture chamber, the blocks were removed. Lesions were examined after 5 days of incubation at room temperature. Segments of plant leaves with blast lesions were excised, surface sterilized, and incubated on water agar for 2 to 3 days to assay conidiophore development as described (Xu and Hamer 1996).

\section{Molecular manipulations and sequence analyses.}

Standard molecular biology procedures were followed for enzymatic manipulations of DNA (Sambrook and Russell 2001). Genomic DNA was extracted from mycelia by the cetyltrimethylammonium bromide protocol (Xu and Hamer 1996). Programs ClustalW and TreeView 32 were used for sequence alignment and construction of the phylogenetic tree. For qRTPCR analysis, RNA samples were isolated from mycelia and conidiophores harvested from 10-day-old oatmeal cultures with the SV total RNA isolation system (Promega Corp., Madison, WI, U.S.A.). First-strand cDNA was synthesized with AMV reverse transcriptase (Promega Corp.). Real-time PCR was performed with the MJ Research OPTICON Real-Time Detection System using the TaKaRa SYBR Premix Ex Taq (Takara, Shiga, Japan). Primer pairs 1QF/1QR, AQF/AQR, BQF/BQR, CQF/ $\mathrm{CQR}$, and BTF/BTR were used to amplify the HTF1, ACRl, $B U F 1, C O N 7$, and $\beta$-tubulin genes, respectively. The relative quantification of each transcript was calculated by the $2^{-\Delta \Delta C t}$ method (Livak and Schmittgen 2001) with the M. oryzae $\beta$ tubulin gene (MGG_00604) as the internal control.

\section{Gene replacement vectors and mutants.}

To generate the HTF1 gene-replacement vector, a $0.91-\mathrm{kb}$ fragment upstream from HTF1 was amplified with primers $1 \mathrm{AF}$ and $1 \mathrm{AR}$ and cloned between the SacI and HindIII sites on pCSN43 as pHT1a. A 0.81-kb fragment downstream from HTF 1 was amplified with primers $1 \mathrm{BF}$ and $1 \mathrm{BR}$ and cloned between the XhoI and KpnI sites on pHT1a as pHT1, which was transformed into protoplasts of the wild-type strain Guy11 as described (Zhao and $\mathrm{Xu} 2007$ ). Hygromycin-resistant transformants were screened by PCR with primers $1 \mathrm{DB}$ and H853 (Table 3). The complementation vector pYH1 was constructed by cloning a 4.7-kb fragment of $H T F 1$ amplified with primers $1 \mathrm{H} 1 \mathrm{~F}$ and $1 \mathrm{H} 2 \mathrm{R}$ between the XhoI and $\mathrm{XbaI}$ sites of pYK11 (Zhao and $\mathrm{Xu}$ 2007). Primers used to generate the constructs and screen for gene replacement mutants are listed in Table 3.

\section{SEM.}

Blocks of 10-day-old oatmeal agar cultures $\left(5 \mathrm{~mm}^{2}\right)$ were fixed in $4 \%$ glutaraldehyde at $4^{\circ} \mathrm{C}$ for $16 \mathrm{~h}$. The samples were then dehydrated in a graded ethanol series and dried in a critical point dryer as described (Zange et al. 2005). After being sputtercoated with gold, conidia and conidiophores were observed with a JSM-6360LV (Jeol Ltd., Tokyo) scanning electron microscope.

\section{Construction of the $H T F 1^{\triangle \mathrm{HD}}$ allele.}

To generate the $H T F 1^{\triangle \mathrm{HD}}$ allele, a $2.2-\mathrm{kb}$ fragment amplified with primers $1 \mathrm{H} 1 \mathrm{~F}$ and $1 \mathrm{H} 1 \mathrm{R}$ (Table 3 ) was cloned into pYK11 between the XhoI and SpeI site as pYK11-H1. A 2.3-kb downstream fragment of $H T F 1$ was amplified with primers $1 \mathrm{H} 2 \mathrm{~F}$ and 1H2R and cloned into the SpeI and SacI site of pYK11-H1. In the resulting construct, pYH12, the HTF1 gene was under the control of its native promoter but amino acid residues 86 to 146 were deleted. All PCR reactions were performed with the $L a$ DNA polymerase (Takara). The pYH12 construct was confirmed by sequencing and transformed into the $\Delta h t f l$ mutant. Primers D1F and D1R were used for RT-PCR to determine the expression of $H T F 1^{\triangle \mathrm{HD}}$ in the resulting transformants.

\section{Generation of the HTF 1-EGFP fusion construct.}

For constructing the $H T F 1$-EGFP fusion vector, $\mathrm{pHN} 1$, the entire $H T F 1$ open reading frame (ORF) and a 1.1-kb upstream promoter sequence were amplified with primers $1 \mathrm{NGF}$ and 1NGR (Table 3). The resulting PCR product was cloned into the bleomycin-resistance vector pKB04 (Bruno et al. 2004) by the in vivo yeast homologous recombination approach (Bourett et al. 2002). To generate the EGFP-HTF1 fusion construct $\mathrm{pHN} 2$, a 1,612-bp fragment upstream from $H T F 1$ as its native promoter was amplified with primers $1612 \mathrm{PF}$ and $1612 \mathrm{PR}$ and cloned between the SacI and SacII sites on pYK11 as pHN2a. A 711-bp fragment of EGFP without stop codon was amplified with primers GFP 717F and GFP 717R and cloned between the SacII and XbaI sites on pHN2a as pHN2b and, then, a 3,175-bp fragment of HTFl ORF and its terminator was amplified with primers $3175 \mathrm{OF}$ and $3175 \mathrm{OR}$ and cloned between the $X b a \mathrm{I}$ and $X h o I$ sites on $\mathrm{pHN} 2 \mathrm{~b}$ as pHN2. Plasmid pHN1 and pHN2 was confirmed by sequencing analysis to carry the HTFl-EGFP and EGFP-HTFl fusion construct under the control of its native promoter. pHN1 and pHN2 were transformed into the $\Delta h t f l$ mutant by selecting for zeocin-resistant transformants (Zhao and $\mathrm{Xu}$ 2007).

\section{ACKNOWLEDGMENTS}

This manuscript was selected as a feature article through the APS/CSPP Cooperative Agreement. We thank L. Dunkle, C. Woloshuk at Purdue University, P. P. Poon, and J. Benjamin at Dalhousie University for critical reading of this manuscript; Z. Kang and Q. Han at Northwest Agricultural University for assistance with SEM examination; H. Liu at Fujian Agriculture and Forestry University for her help in statistical analysis; F. Gao for his help in phylogenetic analysis; and S.-L. Ding at Purdue University for fruitful discussions. This work was supported by the National Basic Research Program of China (2006CB1019001), the 948 project (2006 G61), the Chinese National Science Foundation (30528017), and a grant from the United States Department of Agriculture Cooperative State Research, Education and Extension Service (no. 2007-35319-102681).

\section{LITERATURE CITED}

Aramayo, R., and Metzenberg, R. L. 1996. Meiotic transvection in fungi. Cell 86:103-113.

Arnaise, S., Zickler, D., Poisier, C., and Debuchy, R. 2001. pah1: A homeobox gene involved in hyphal morphology and microconidiogenesis in the filamentous ascomycete Podospora anserina. Mol. Microbiol. 39:54-64.

Bakkeren, G., Kamper, J., and Schirawski, J. 2008. Sex in smut fungi: structure, function and evolution of mating-type complexes. Fungal Genet. Biol. 45:S15-S21.

Bhoite, L. T., Allen, J. M., Garcia, E., Thomas, L. R., Gregory, I. D., Voth, W. P., Whelihan, K., Rolfes, R. J., and Stillman, D. J. 2002. Mutations in the Pho2 (Bas2) transcription factor that differentially affect activation with its partner proteins Bas1, Pho4, and Swi5. J. Biol. Chem. 277:37612-37618.

Bourett, T. M., Sweigard, J. A., Czymmek, K. J., Carroll, A., and Howard, R. J. 2002. Reef coral fluorescent proteins for visualizing fungal pathogens. Fungal Genet. Biol. 37:211-220.

Briata, P., Ilengo, C., Bobola, N., and Corte, G. 1999. Binding properties of the human homeodomain protein $O T X 2$ to a DNA target sequence. FEBS (Fed. Eur. Biochem. Soc.) Lett. 445:160-164.

Bruno, K. S., Tenjo, F., Li, L., Hamer, J. E., and Xu, J. R. 2004. Cellular localization and role of kinase activity of $P M K 1$ in Magnaporthe grisea. Eukaryot. Cell 3:1525-1532.

Chao, C. T., and Ellingboe, A. H. 1991. Selection for mating competence in Magnaporthe grisea pathogenic to rice. Can. J. Bot. 69:2130-2134

Chen, J. S., Zheng, W, Zheng, S. Q., Zhang, D. M., Sang, W. J., Chen, X., 
Li, G. P., Lu, G. D., and Wang, Z. H. 2008. Rac1 is required for pathogenicity and Chm1-dependent conidiogenesis in rice fungal pathogen Magnaporthe grisea. PLoS Pathog. 4(11):e1000202.

Colot, H. V., Park, G., Turner, G. E., Ringelberg, C., Crew, C. M. Litvinkova, L., Weiss, R. L., Borkovich, K. A., and Dunlap, J. C. 2006. A high-throughput gene knockout procedure for Neurospora reveals functions for multiple transcription factors. Proc. Natl. Acad. Sci. U.S.A. 103:10352-10357.

Deng, Y. Z., Ramos-Pamplona, M., and Naqvi, N. 2009. Autophagyassisted glycogen catabolism regulates asexual differentiation in Magnaporthe oryzae. Autophagy 5:33-43

Dufresne, M., and Osbourn A. E. 2001. Definition of tissue-specific and general requirements for plant infection in a phytopathogenic fungus. Mol. Plant-Microbe Interact. 14:300-307.

Ebbole, D. J. 2007. Magnaporthe as a model for understanding hostpathogen interactions. Annu. Rev. Phytopathol. 45:437-456.

Fang, E. G. C., and Dean, R. A. 2000. Site-directed mutagenesis of the $M A G B$ gene affects growth and development in Magnaporthe grisea. Mol. Plant-Microbe Interact. 13:1214-1227.

Ganem, S., Lu, S. W., Lee, B. N., Chou, D. Y. T., Hadar, R., Turgeon, B G., and Horwitz, B. A. 2004. G-protein beta subunit of Cochliobolus heterostrophus involved in virulence, asexual and sexual reproductive ability, and morphogenesis. Eukaryot. Cell 3:1653-1663.

Gehring, W. J., and Hiromi, Y. 1986. Homeotic genes and the homeobox. Annu. Rev. Genet. 20:147-173.

Horak, C. E., Luscombe, N. M., Qian, J. A., Bertone, P., Piccirrillo, S. Gerstein, M., and Snyder, M. 2002. Complex transcriptional circuitry at the G1/S transition in Saccharomyces cerevisiae. Genes Dev. 16:30173033.

Houston, M. E., Ho, C. Y., Adamson, J. G., Hodges, R. S., and Smith, M. 2002. A possible mechanism for partitioning between homo- and heterodimerization of the yeast homeodomain proteins MATa1 and MAT alpha 2. J. Peptide Res. 59:34-43.

Hull, C. M., Boily, M. J., and Heitman, J. 2005. Sex-specific homeodomain proteins Sxi1 alpha and Sxi2a coordinately regulate sexual development in Cryptococcus neoformans. Eukaryot. Cell 4:526-535.

Jeon, J., Park, S. Y., Chi, M. H., Choi, J., Park, J., Rho, H. S., Kim, S., Goh, J., Yoo, S., Choi, J., Park, J. Y., Yi, M., Yang, S., Kwon, M. J., Han, S. S., Kim, B. R., Khang, C. H., Park, B., Lim, S. E., Jung, K., Kong, S., Karunakaran, M., Oh, H. S., Kim, H., Kim, S., Park, J., Kang, S., Choi, W. B., Kang, S., and Lee, Y. H. 2007. Genome-wide functional analysis of pathogenicity genes in the rice blast fungus. Nat. Genet. 39:561-565.

Kanamori, M., Kato, H., Yasuda, N., Koizumi, S., Peever, T. L., Kamakura T., Teraoka, T., and Arie, T. 2007. Novel mating type-dependent transcripts at the mating type locus in Magnaporthe oryzae. Gene 403:6-17.

Kankanala, P., Czymmek, K., and Valent, B. 2007. Roles for rice membrane dynamics and plasmodesmata during biotrophic invasion by the blast fungus. Plant Cell 19:706-724.

Krystofova, S., and Borkovich, K. A. 2006. The predicted G-protein-coupled receptor $G P R-1$ is required for female sexual development in the multicellular fungus Neurospora crassa. Eukaryot. Cell 5:1503-1516.

Kunoh, T., Kaneko, Y., and Harashima, S. 2000. YHP1 encodes a new homeoprotein that binds to the IME1 promoter in Saccharomyces cerevisiae. Yeast 16:439-449.

Lau, G. W., and Hamer, J. E. 1998. Acropetal: a genetic locus required for conidophore architecture and pathogenicity in the rice blast fungus. Fungal Genet. Biol. 24:228-239.

Livak, K. J., and Schmittgen, T. D. 2001. Analysis of relative gene expression data using real-time quantitative PCR and the $2(\mathrm{~T})(-$ delta delta $\mathrm{C})$ method. Methods 25:402-408.

Lockhart, S. R., Wu, W., Radke, J. B., Zhao, R., and Soll, D. R. 2005. Increased virulence and competitive advantage of a/alpha over a/a or alpha/alpha offspring conserves the mating system of Candida albicans. Genetics 169:1883-1890.

Mah, J. H., and Yu, J. H. 2006. Upstream and downstream regulation of asexual development in Aspergillus fumigatus. Eukaryot. Cell 5:15851595

Miller, M. G., and Johnson, A. D. 2002. White-opaque switching in Candida albicans is controlled by mating-type locus homeodomain proteins and allows efficient mating. Cell 110:293-302.

Mitchell, T. K., and Dean, R. A. 1995. The cAMP-dependent protein kinase catalytic subunit required for appressorium formation and pathogenesis by the rice blast pathogen Magnaporthe grisea. Plant Cell 7:1869-1878

Nishimura, M., Hayashi, N., Jwa, N. S., Lau, G. W., Hamer, J. E., and Hasebe, A. 2000. Insertion of the LINE retrotransposon MGL causes a conidiophore pattern mutation in Magnaporthe grisea. Mol. Plant-Microbe Interact. 13:892-894.

Nishimura, M., Park, G., and Xu, J. R. 2003. The G-beta subunit MGB1 is involved in regulating multiple steps of infection-related morphogenesis in Magnaporthe grisea. Mol. Microbiol. 50:231-243.

Odenbach, D., Breth, B., Thines, E., Weber, R. W. S., Anke, H., and Foster, A. J. 2007. The transcription factor Con $7 p$ is a central regulator of infection-related morphogenesis in the rice blast fungus Magnaporthe grisea. Mol. Microbiol. 64:293-307.

Park, G., Xue, C. Y., Zheng, L., Lam, S., and Xu, J. R. 2002. MST12 Regulates infectious growth but not appressorium formation in the rice blast fungus Magnaporthe grisea. Mol. Plant-Microbe Interact. 15:183192.

Park, G., Bruno, K. S., Staiger, C. J., Talbot, N. J., and Xu, J. R. 2004. Independent genetic mechanisms mediate turgor generation and penetration peg formation during plant infection in the rice blast fungus. Mol. Microbiol. 53:1695-1707.

Park, G., Xue, C., Zhao, X., Kim, Y., Orbach, M., and Xu, J. R. 2006. Multiple upstream signals converge on the adaptor protein Mst50 in Magnaporthe grisea. Plant Cell 18:2822-2835.

Pramila, T., Miles, S., GuhaThakurta, D., Jemiolo, D., and Breeden, L. L. 2002. Conserved homeodomain proteins interact with MADS box protein $\mathrm{Mcm} 1$ to restrict ECB-dependent transcription to the M/G1 phase of the cell cycle. Genes Dev. 16:3034-3045.

Sambrook, J., and Russell, D. 2001 Molecular Cloning-A Laboratory Manual. Cold Spring Harbor Laboratory Press, Cold Spring Harbor, NY, U.S.A.

Scott, M. P., Tamkun, J. W., and Hartzell, G. W. 1989. The structure and function of the homeodomain. Biochem. Biophys. Acta 989:25-48.

Shi, Z. X., Christian, D., and Leung, H. 1998. Interactions between spore morphogenetic mutations affect cell types, sporulation, and pathogenesis in Magnaporthe grisea. Mol. Plant-Microbe Interact. 11:199-207.

Svingen, T., and Tonissen, K. F. 2006. Hox transcription factors and their elusive mammalian gene targets. Heredity 97:88-96.

Sweigard, J. A., Carroll, A. M., Farrall, L., Chumley, F. G., and Valent, B. 1998. Magnaporthe grisea pathogenicity genes obtained through insertional mutagenesis. Mol. Plant-Microbe Interact. 11:404-412.

Talbot, N. J. 2003. On the trail of a cereal killer: exploring the biology of Magnaporthe grisea. Annu. Rev. Microbiol. 57:177-202.

Teng, P. S, Klein-Gebbinck, H. W., and Pinnschmidt, H. 1991. An analysis of the blast pathosystem to guide modeling and forecasting. Pages 1-30 in: Rice Blast Modeling and Forecasting. International Rice Research Institute, Los Baños, The Philippines.

Torres-Guzman, J. C., and Dominguez, A. 1997. HOY1, a homeo gene required for hyphal formation in Yarrowia lipolytica. Mol. Cell. Biol. 17:6283-6293.

Xia, Z. X., Turner, G. C., Hwang, C. S., Byrd, C., and Varshavsky, A. 2008. Amino acids induce peptide uptake via accelerated degradation of $C U P 9$, the transcriptional repressor of the PTR2 peptide transporter. J. Biol. Chem. 283:28958-28968.

Xu, D., Jiang, B., Ketela, T., Lemieux, S., Veillette, K., Martel, N., Davison, J., Sillaots, S., Trosok, T., Bachewich, C., Bussey, H., Youngman, P., and Roemer, T. 2007a. Genome-wide fitness test and mechanism-ofaction studies of inhibitory compounds in Candida albicans. PLoS Pathog. 3:e92.

Xu, J. R., and Hamer, J. E. 1996. MAP kinase and cAMP signaling regulate infection structure formation and pathogenic growth in the rice blast fungus Magnaporthe grisea. Genes Dev. 10:2696-2706.

Xu, J. R., Zhao, X., and Dean, R. A. 2007b. From genes to genomes: a new paradigm for studying fungal pathogenesis in Magnaporthe oryzae. Adv. Genet. 57:175-218

Yu, J. H., Mah, J. H., and Seo, J. A. 2006. Growth and developmental control in the model and pathogenic aspergilli. Eukaryot. Cell 5:1577-1584.

Zange, B. J., Kang, Z., and Buchenauer, H. 2005. Effect of Folicur (R) on infection process of Fusarium culmorum in wheat spikes. J. Plant Dis. Prot. 112:52-64.

Zhao, X., Kim, Y., Park, G., and Xu, J. R. 2005. A mitogen-activated protein kinase cascade regulating infection-related morphogenesis in Magnaporthe grisea. Plant Cell 17:1317-1329.

Zhao, X. H., and Xu, J. R. 2007. A highly conserved MAPK-docking site in Mst7 is essential for Pmk1 activation in Magnaporthe grisea. Mol. Microbiol. 63:881-894.

Zhou, Z., Li, G., Lin, C., and He, C. 2009. Conidiophore stalk-less1 encodes a putative zinc-finger protein involved in the early stage of conidiation and mycelial infection in Magnaporthe oryzae. Mol. Plant-Microbe Interact. 22:402-410

\section{AUTHOR-RECOMMENDED INTERNET RESOURCES}

Broad Institute Magnaporthe oryzae database: www.broadinstitute.org/annotation/fungi/magnaporthe

National Institutes of Health National Human Genome Research Institute website: research.nhgri.nih.gov 